\title{
BMJ open Passive smoking and chronic obstructive pulmonary disease: cross-sectional analysis of data from the Health Survey
for England
}

\author{
Rachel E Jordan, ${ }^{1}$ Kar Keung Cheng, ${ }^{1}$ Martin R Miller, ${ }^{2}$ Peymané Adab ${ }^{1}$
}

To cite: Jordan RE, Cheng $\mathrm{KK}$, Miller MR, et al. Passive smoking and chronic obstructive pulmonary disease: cross-sectional analysis of data from the Health Survey for England. BMJ Open 2011;1:e000153. doi:10.1136/bmjopen-2011000153

- Prepublication history for this paper is available online. To view these files please visit the journal online (http:// bmjopen.bmj.com).

Received 28 April 2011 Accepted 21 July 2011

This final article is available for use under the terms of the Creative Commons Attribution Non-Commercial 2.0 Licence; see http://bmjopen.bmj.com

${ }^{1}$ Unit of Public Health, Epidemiology and Biostatistics, University of Birmingham, Birmingham, UK ${ }^{2}$ Institute of Occupational and Environmental Medicine, University of Birmingham, Birmingham, UK

Correspondence to Dr Rachel E Jordan; r.e.jordan@bham.ac.uk

\section{ABSTRACT}

Objectives: There is increasing evidence that passive smoking is associated with chronic respiratory diseases, but its association with chronic obstructive pulmonary disease (COPD) requires more study. In this cross-sectional analysis of data from 3 years of the Health Survey for England, the association between passive smoking exposure and risk of COPD is evaluated.

Design: Cross-sectional analysis of the 1995, 1996 and 2001 Health Surveys for England including participants of white ethnicity, aged $40+$ years with valid lung function data. COPD was defined using the lower limit of normal spirometric criteria for airflow obstruction. Standardised questions elicited selfreported information on demography, smoking history, ethnicity, occupation, asthma and respiratory symptoms (dyspnoea, chronic cough, chronic phlegm, wheeze). Passive smoking was measured by selfreport of hours of exposure to cigarette smoke per week.

Results: Increasing passive smoke exposure was independently associated with increased risk of COPD, with adjusted OR $1.05(95 \% \mathrm{Cl} 0.93$ to 1.18) for $1-19 \mathrm{~h}$ and $\mathrm{OR} 1.18$ (95\% Cl 1.01 to 1.39$)$ for 20 or more hours of exposure per week. Similar patterns (although attenuated and non-significant) were observed among never smokers. More marked dose-response relationships were observed between passive smoking exposure and respiratory symptoms, but the most marked effects were on the development of clinically significant COPD (airflow obstruction plus symptoms), where the risk among never smokers was doubled (OR $1.98(95 \% \mathrm{Cl} 1.03$ to 3.79$)$ ) if exposure exceeded $20 \mathrm{~h} /$ week.

Conclusion: This analysis adds weight to the evidence suggesting an association between passive smoking exposure and COPD.

\section{INTRODUCTION}

Active smoking is accepted as the most important risk factor for the development of chronic obstructive pulmonary disease (COPD), and is responsible for over $70 \%$ of

\section{ARTICLE SUMMARY}

\section{Article focus}

- Passive exposure to cigarette smoke is established as an important independent risk factor for the development of chronic conditions such as heart disease and lung cancer.

- Although there is growing evidence implicating passive smoking in asthma and other respiratory diseases, the evidence for its effect on chronic obstructive pulmonary disease (COPD) is inconsistent.

- Using cross-sectional data from the annual Health Survey for England, we examined the association between self-reported exposure to passive smoking and COPD.

\section{Key messages}

- We have demonstrated a significant dose-response relationship between hours of exposure to passive smoking and increasing risk of COPD.

- The most marked effects were observed on the development of clinically significant COPD (airflow obstruction plus symptoms), where the risk among never smokers was doubled (OR 1.98 $(95 \% \mathrm{Cl} 1.03$ to 3.79$))$ if exposure exceeded $20 \mathrm{~h} /$ week.

- Passive smoking is prevalent worldwide, and even after the 2007 public smoking ban in the UK, $20 \%$ of the adult English population are still exposed to up to $20 \mathrm{~h}$ of passive smoking per week, with $5 \%$ exposed to more than $20 \mathrm{~h} /$ week; further measures are needed to investigate and reduce exposures in the home and elsewhere.

cases in high income countries, although far fewer $(\sim 40 \%)$ in lower income countries. ${ }^{1}$ The remaining risk is attributed to a number of environmental factors, including occupational exposure to dust and fumes, and indoor and outdoor air pollution. ${ }^{2}$

Passive exposure to cigarette smoke is accepted as an independent risk factor for heart disease and lung cancer, ${ }^{34}$ and has also been implicated in the aetiology of COPD, ${ }^{25}$ although the association between passive 


\section{ARTICLE SUMMARY}

Strengths and limitations of this study

- Our study has the advantage of being a large sample representative of the English population ( $>21000$ participants), conducted over 3 separate years, with a standardised protocol and objective measure of lung function.

- However, due to the cross-sectional nature of the design, temporal associations cannot necessarily be inferred.

- The Health Survey for England was not designed for the specific analyses presented in this paper, and thus some of the measures are crude.

- Self-reported passive smoke exposure is only a proxy for true exposure levels, but is accepted as the most practical method of assessment.

smoking and COPD is less well defined. There is increasing evidence that passive smoking is an important risk factor in chronic respiratory diseases. A number of studies suggest that asthma can be induced by exposure to passive smoking, ${ }^{6}$ and there is strong evidence to suggest that passive smoking increases the risk of general respiratory symptoms. ${ }^{6-11}$ Many previous studies have also examined the relationship between passive smoking and lung function, but with inconsistent results. ${ }^{6}$ Evidence is now emerging that COPD may be independently associated with passive smoking exposure, ${ }^{7} 11-18$ although a recent editorial ${ }^{19}$ highlighted that more studies were required before a causal role could be established.

One difficulty with evaluating such an association is the number of subjects required to demonstrate the relatively small RRs associated with passive smoking risks (in the region of 1.2-1.5). ${ }^{12} 13$ The Health Survey for England (HSE) has the advantage of size (over 15000 adults are surveyed every year), generalisability and a standard protocol which is repeated annually. In 1995, 1996 and 2001, lung function was measured, providing the opportunity to examine the association between passive smoking and COPD in large numbers of people. The large size also allows the analysis to be restricted to never smokers, thus reducing any misclassification of reported exposure to passive smoking which could occur among smokers.

\section{METHODS}

\section{Study design}

Cross-sectional analysis of data collected by the annual HSE in 1995, 1996 and 2001, was carried out to establish the association between passive smoking and COPD.

\section{Setting}

The HSE is part of a set of annual surveys designed to monitor population health. The dataset is publicly available and obtained from the UK Data archive. ${ }^{20}$ Briefly, an independent general population sample was surveyed each year obtained by multistage stratified random sampling of private households in
England. ${ }^{21-23}$ Postcode sectors were sorted by health authority and, within each health authority by the percentage of households where the head of the household had a non-manual occupation. A total of 720 postcode sectors were selected, with the probability of selection proportional to the number of delivery points (or addresses) in each sector. Nineteen addresses were selected from each sector. (Selecting sectors and addresses in this way ensures each household has an equal probability of selection.) Up to three households could be selected in any one postcode address. Home interviews and health assessments by trained interviewers and nurses were carried out for over 15000 different adults each year. In 1995, 1996 and 2001, an assessment of lung function ( $\mathrm{FEV}_{1}, \mathrm{FVC}$ and PEF) was included, and in 1995 and 1996, information on respiratory health was additionally collected. Data from all 3 years were combined with adjustment for year of study in the analyses.

\section{Participants}

Participants of white ethnicity, aged 40 years and above and with valid lung function tests and height data were included in the analysis. Because only pre-bronchodilator spirometry was available, participants reporting a diagnosis of asthma were excluded from the main analyses but included in sensitivity analyses. Analyses were carried out among all participants and separately among never smokers.

\section{Questionnaire and procedures}

All consenting participants within the HSE were administered a detailed standardised computer-assisted interview used in previous survey years and seeking information on demographic characteristics, smoking history, ethnicity, occupation and educational level. Socioeconomic status was grouped into non-manual occupations and manual/other occupations. Participants were specifically asked if they had ever been diagnosed with asthma and whether they experienced a range of respiratory symptoms. Standard questions about wheeze, dyspnoea, chronic cough and chronic phlegm were included:

Wheeze: yes to either of:

Have you had wheezing or whistling in the chest in the last 12 months?

In the past 12 months, have you been woken by an attack of shortness of breath?

Dyspnoea: yes to any of:

Are you troubled by shortness of breath when hurrying on level ground or walking up a slight hill?

Do you get short of breath walking with other people of your own age on level ground?

Do you have to stop for breath when walking at your own pace on level ground?

Chronic cough: yes to either of the first two and yes to 3 months of coughing

Do you usually cough first thing in the morning in winter? 
Table 1 Characteristics of included and excluded participants

\begin{tabular}{|c|c|c|c|c|c|}
\hline & \multicolumn{4}{|c|}{ Included participants } & \multirow{2}{*}{$\begin{array}{l}\text { Excluded } \\
\text { participants }\end{array}$} \\
\hline & 1995 & 1996 & 2001 & Total & \\
\hline$n$ & 7071 & 7565 & 6468 & 21104 & 6549 \\
\hline Males & $3303(46.7 \%)$ & $3551(46.9 \%)$ & $2993(46.3 \%)$ & $9847(46.7 \%)$ & $2616(40.0 \%)$ \\
\hline Mean age, years (SD) & $58.4(12.3)$ & $58.1(12.3)$ & $57.9(11.9)$ & $58.1(12.2)$ & $63.9(14.3)$ \\
\hline \multicolumn{6}{|l|}{ Age group } \\
\hline $40-49$ & $2129(30.1 \%)$ & 2409 (31.8\%) & $1872(28.9 \%)$ & $6410(30.4 \%)$ & $1389(21.2 \%)$ \\
\hline $50-59$ & $1812(25.6 \%)$ & $1876(24.8 \%)$ & $1954(30.2 \%)$ & $5642(26.7 \%)$ & $1290(19.7 \%)$ \\
\hline $60-69$ & $1598(22.6 \%)$ & $1695(22.4 \%)$ & $1380(21.3 \%)$ & $4673(22.1 \%)$ & $1317(20.1 \%)$ \\
\hline $70-79$ & $1158(16.4 \%)$ & $1186(15.7 \%)$ & 969 (15.0\%) & $3313(15.7 \%)$ & $1418(21.7 \%)$ \\
\hline $80+$ & $374(5.3 \%)$ & $399(5.3 \%)$ & $293(4.5 \%)$ & $1066(5.1 \%)$ & 1135 (17.3\%) \\
\hline \multicolumn{6}{|l|}{ Socioeconomic status $†$} \\
\hline Non-manual occupations & 3928 (56.4\%) & $4195(56.2 \%)$ & $3683(57.8 \%)$ & $11806(56.7 \%)$ & $3117(49.6 \%)$ \\
\hline Manual occupations & $3028(43.4 \%)$ & $3254(43.6 \%)$ & $2676(42.0 \%)$ & $8958(43.1 \%)$ & $3158(50.2 \%)$ \\
\hline Other & $14(0.2 \%)$ & $17(0.2 \%)$ & $13(0.2 \%)$ & $44(0.2 \%)$ & $13(0.2 \%)$ \\
\hline \multicolumn{6}{|l|}{ Smoking status $†$} \\
\hline Current & $1612(22.8 \%)$ & $1806(23.9 \%)$ & $1327(20.5 \%)$ & $4745(22.5 \%)$ & $1536(23.5 \%)$ \\
\hline Ex-regular & 2569 (36.4\%) & 2637 (34.9\%) & 2290 (35.4\%) & $7496(35.5 \%)$ & 2237 (34.2\%) \\
\hline Never regular & 2887 (40.9\%) & $3122(41.3 \%)$ & $2850(44.1 \%)$ & $8859(42.0 \%)$ & 2775 (42.4\%) \\
\hline \multicolumn{6}{|l|}{ Pack years smoked } \\
\hline 0 & 3107 (44.0\%) & $3359(44.4 \%)$ & $3038(47.0 \%)$ & $9504(45.0 \%)$ & $2973(45.4 \%)$ \\
\hline $1-19$ & $1817(25.7 \%)$ & $1922(25.4 \%)$ & $1656(25.6 \%)$ & $5395(25.6 \%)$ & $1517(23.2 \%)$ \\
\hline $20-49$ & $1695(24.0 \%)$ & $1803(23.8 \%)$ & $1389(21.5 \%)$ & $4887(23.2 \%)$ & $1552(23.7 \%)$ \\
\hline $50+$ & $449(6.4 \%)$ & $481(6.4 \%)$ & $384(5.9 \%)$ & $1314(6.2 \%)$ & $506(7.7 \%)$ \\
\hline \multicolumn{6}{|l|}{ Exposure to passive smoking, $\mathrm{h}$} \\
\hline Mean hours per week (SD) & $9.2(18.4)$ & $9.3(18.3)$ & $6.1(13.8)$ & $8.3(17.1)$ & $7.0(16.3)$ \\
\hline $\begin{array}{l}\text { Median hours per week } \\
\text { (IQR) }\end{array}$ & $2(0-8)$ & $2(0-8)$ & $1(0-5)$ & $1(0-7)$ & $0(0-5)$ \\
\hline 0 & $2859(40.5 \%)$ & $3111(41.2 \%)$ & $3167(49.1 \%)$ & 9137 (43.4\%) & $3425(52.6 \%)$ \\
\hline $1-9$ & $2540(36.0 \%)$ & $2665(35.3 \%)$ & $2193(34.0 \%)$ & $7398(35.1 \%)$ & $1883(28.9 \%)$ \\
\hline $10-19$ & $667(7.9 \%)$ & $560(7.4 \%)$ & $440(6.8 \%)$ & $1557(7.4 \%)$ & $425(6.5 \%)$ \\
\hline $20+$ & $1105(15.7 \%)$ & $1224(16.2 \%)$ & $657(10.2 \%)$ & $2986(14.2 \%)$ & $778(12.0 \%)$ \\
\hline Any respiratory symptoms $\ddagger$ & $3120(44.1 \%)$ & $3340(44.2 \%)$ & - & $6460(44.1 \%)$ & $1823(47.7 \%)$ \\
\hline Physician-diagnosed asthma & $692(9.8 \%)$ & $794(10.5 \%)$ & $801(12.4 \%)$ & $2287(10.8 \%)$ & $702(10.7 \%)$ \\
\hline \multicolumn{6}{|l|}{ COPD§ } \\
\hline LLN & $675(10.6 \%)$ & $593(8.8 \%)$ & $414(7.3 \%)$ & $1682(8.9 \%)$ & - \\
\hline GOLD & $1190(18.7 \%)$ & $1086(16.1 \%)$ & $757(13.4 \%)$ & $3033(16.1 \%)$ & - \\
\hline NICE & $526(8.3 \%)$ & $443(6.6 \%)$ & $333(5.9 \%)$ & $1302(6.9 \%)$ & - \\
\hline
\end{tabular}

${ }^{*}$ Excluded due to invalid lung function or height measurements.

+Missing data: 557/27653 (2.0\%) had missing socioeconomic status and 5/27653 (0.02\%) missing smoking history.

$\neq$ Dyspnoea, wheeze, chronic cough or phlegm. Not recorded in 2001.

$\S$ Among those without asthma: GOLD criteria 26 : $\mathrm{FEV}_{1} / \mathrm{FVC}$ ratio $<0.7 ; \mathrm{NICE}$ criteria: $\mathrm{FEV}_{1} / \mathrm{FVC}<0.7$ and $\mathrm{FEV}_{1}<80 \%$ predicted (equivalent to GOLD stage II) ${ }^{27}$; lower limit of normal (LLN) criteria ${ }^{24}$ 25: participants with FEV 1 /FVC values $>1.645$ SD below the mean reference value.

COPD, chronic obstructive pulmonary disease.

Do you usually cough during the day or at night in the winter?

Do you cough like this on most days for as much as 3 months each year?

Chronic phlegm: yes to either of the first two and yes to 3 months of phlegm

Do you usually bring up any phlegm from your chest, first thing in the morning in winter?

Do you usually bring up any phlegm from your chest, during the day or at night in the winter?

Do you bring up phlegm like this on most days for as much as 3 months each year?

Smoking habit was defined as current, ex- and never regular smokers (where regular was defined as at least one cigarette per day). Passive smoking exposure was measured by self-report of the number of hours currently exposed to cigarette smoke per week: "Now, in most weeks, how many hours a week are you exposed to other people's tobacco smoke?" As there was no lifetime indicator of chronic passive smoking exposure, this was assumed to be indicative of past adult exposure, aided by the data being collected before the 2007 public smoking ban in England.

Among other measurements, pulmonary function tests, without reversibility, were performed according to a standard protocol ${ }^{18-20}$ with a Vitalograph (Maids Moreton, Buckinghamshire, UK) Escort spirometer (Fleisch pneumotachograph flow head) which was 


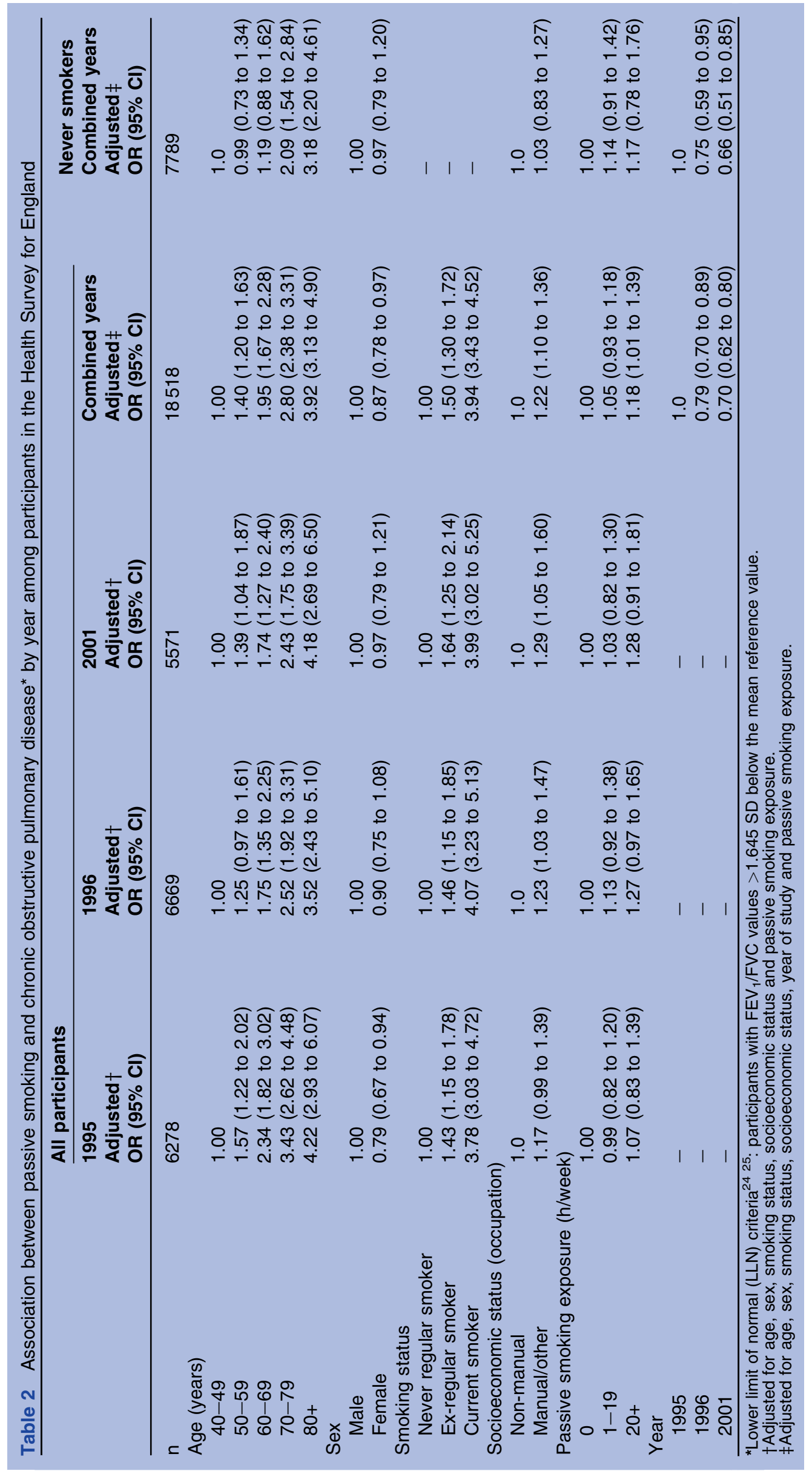


calibrated daily at normal room temperature. The best $\mathrm{FEV}_{1}$ and FVC measurements were used.

\section{Outcomes}

The main outcome measure was the presence of COPD, defined by using the reference equations from the European Community for Steel and Coal Study ${ }^{24}$ and the lower limit of normal (LLN) criterion. ${ }^{25}$ In this way, participants were classified as having obstructive airways disease if their pre-bronchodilator $\mathrm{FEV}_{1} / \mathrm{FVC}$ values were below the lowest $5 \%$ of the frequency distribution of values found in the healthy reference population. Secondary outcome measures were the presence of any chronic respiratory symptoms (wheeze, dyspnoea, chronic cough, chronic phlegm, as detailed above) and the presence of clinically significant COPD (both airflow obstruction (LLN) and any of the above respiratory symptoms). Analyses were repeated using both pre-bronchodilator modified $\mathrm{GOLD}^{26}\left(\mathrm{FEV}_{1} /\right.$ FVC ratio $<0.7)$ and NICE criteria ${ }^{27}\left(\mathrm{FEV}_{1} / \mathrm{FVC}<0.7\right.$ and $\mathrm{FEV}_{1}<80 \%$ predicted, equivalent to GOLD stage II). Because lung function data were pre-bronchodilator, some patients with airflow obstruction could have asthma rather than COPD. The analyses were initially undertaken excluding participants with asthma and then repeated including participants with asthma.

\section{Statistical analysis}

Univariate and multivariate logistic regression were undertaken in STATA V.10.0, in the latter adjusting for age, sex, smoking history, year of study, socioeconomic status and self-reported asthma where appropriate and adding significantly to the statistical model.

\section{RESULTS}

\section{Study participants}

Of 27653 white adults aged 40 years and older, 6549 $(23.7 \%)$ were excluded because they did not have valid lung function data or a reliable height measurement.

Table 1 describes the baseline characteristics of the remaining included participants, by year and compared with the excluded participants. The mean age of the participants was 58.1 years (SD 12.2) and 9847 (46.7\%) were male. Age and sex distributions were similar for each year. Overall, 4745 (22.5\%) were current smokers and $8859(42.0 \%)$ had never smoked regularly; there were fewer current and more never smokers in 2001 compared with previous years. Most smokers had smoked less than 50 pack-years.

Exposure to passive smoking declined over time, with $2859(40.5 \%)$ experiencing no exposure in 1995, which increased to $3167(49.1 \%)$ by 2001 . Numbers exposed in the highest exposure group (20 or more hours per week) dropped from $1105(15.7 \%)$ in 1995 to 657 $(10.2 \%)$ in 2001.

COPD prevalence among participants without asthma (LLN criteria) also decreased from $10.6 \%$ in 1995 to
Table 3 Association between passive smoking and respiratory symptoms and clinically significant chronic obstructive pulmonary disease among never-smoking participants of the Health Survey for England, 1995/1996

\begin{tabular}{|c|c|c|}
\hline & $\begin{array}{l}\text { Respiratory } \\
\text { symptoms* } \\
\text { Adjusted OR } \neq \\
(95 \% \mathrm{Cl})\end{array}$ & $\begin{array}{l}\text { Clinically significant } \\
\text { COPD } \dagger \\
\text { Adjusted OR } \ddagger \\
(95 \% \mathrm{Cl})\end{array}$ \\
\hline $\mathrm{n}$ & 5441 & 5441 \\
\hline \multicolumn{3}{|c|}{ Age (years) } \\
\hline $40-49$ & 1.00 & 1.00 \\
\hline $50-59$ & $1.37(1.16$ to 1.62$)$ & $1.46(0.74$ to 2.87$)$ \\
\hline $60-69$ & $2.03(1.72$ to 2.40$)$ & $2.73(1.46$ to 5.10$)$ \\
\hline $70-79$ & $3.06(2.54$ to 3.68$)$ & $6.33(3.48$ to 11.54$)$ \\
\hline $80+$ & 4.22 (3.29 to 5.40$)$ & 11.08 (5.76 to 21.30$)$ \\
\hline \multicolumn{3}{|l|}{ Sex } \\
\hline Male & 1.00 & 1.00 \\
\hline Female & $1.32(1.17$ to 1.50$)$ & $0.99(0.67$ to 1.44$)$ \\
\hline \multicolumn{3}{|l|}{ Year } \\
\hline 1995 & 1.00 & 1.00 \\
\hline 1996 & $0.97(0.87$ to 1.09$)$ & $0.61(0.42$ to 0.87$)$ \\
\hline \multicolumn{3}{|c|}{ Passive smoking exposure (h/week) } \\
\hline 0 & 1.00 & 1.00 \\
\hline $1-19$ & 1.20 (1.06 to 1.37$)$ & 1.52 (1.04 to 2.23$)$ \\
\hline $20+$ & 1.68 (1.36 to 2.08$)$ & $1.98(1.03$ to 3.79$)$ \\
\hline
\end{tabular}

${ }^{*}$ Respiratory symptoms: any of dyspnoea, wheeze, chronic cough or phlegm.

+Lower limit of normal (LLN) criteria ${ }^{24} 25$ : participants with $\mathrm{FEV}_{1}$ / FVC values $>1.645 \mathrm{SD}$ below the mean reference value plus respiratory symptoms.

¥Adjusted for age, sex, passive smoking exposure and year of study.

COPD, chronic obstructive pulmonary disease.

$7.3 \%$ in 2001. COPD measured by modified GOLD or NICE criteria showed similar patterns, although absolute prevalence values differed by definition.

Excluded participants (table 1) were more likely to be older, female, have manual occupations and greater respiratory symptoms but lower current exposure to passive smoking.

\section{Association between passive smoking and COPD}

For each of the 3 years, risk of COPD increased with increasing age and was highest among current smokers compared with never regular smokers, and manual workers compared with non-manual workers (table 2). Females had a lower risk (OR 0.87 (95\% CI 0.78 to 0.97 ) for combined data). Exposure to passive smoking was associated with increased risk of COPD, although for individual years this effect was not statistically significant. For the combined data, increasing exposure to passive cigarette smoke was independently associated with increased risk of COPD, with OR 1.05 (95\% CI 0.93 to 1.18) for up to $20 \mathrm{~h}$ and OR 1.18 (1.01 to 1.39 ) for 20 or more hours of exposure per week once year of study and socioeconomic status were taken into account. Restricting the analyses to never regular smokers resulted in similar patterns, but with a lower sample size $(\mathrm{n}=7789)$ the risk estimates became non-significant (OR 
1.14 (0.91 to 1.42 ) and 1.17 (0.78 to 1.76 ) for $1-19$ and $\geq 20 \mathrm{~h}$ of exposure, respectively).

\section{Effect of passive smoking on respiratory symptoms}

The effect of passive smoking exposure on respiratory symptoms is shown in table 3 (data from 1995 and 1996). Never-smoking participants with increasing exposure to passive smoking were at increased risk of reporting respiratory symptoms, with OR 1.20 (1.06 to 1.37) for exposure levels of $1-19 \mathrm{~h} /$ week and OR 1.68 (1.36 to 2.08 ) for $\geq 20 \mathrm{~h}$ of exposure. Notably, there was a significantly increased risk among females compared with males of reporting any respiratory symptoms (OR 1.32 (1.17 to 1.50$))$.

Furthermore, the risk of clinically significant COPD (ie, having both respiratory symptoms and evidence of airflow obstruction by spirometry) among never-smoking participants exposed to passive smoking was higher than the risk of symptoms alone (OR 1.52 (1.04 to 2.23) for $1-19 \mathrm{~h}$ and 1.98 (1.03 to 3.79 ) for $\geq 20 \mathrm{~h} /$ week of exposure).

\section{Sensitivity analyses}

Repeating the analyses with alternative spirometric criteria for COPD showed similar patterns (table 4). However, males and those who were older showed increased independent risks of COPD with both these definitions. Inclusion of participants reporting asthma (table 5) led to similar patterns of the effect of passive smoking on COPD and respiratory symptoms, although sometimes loss of significance for the two outcomes which included airflow obstruction.

\section{DISCUSSION}

In this population-based analysis of over 21000 subjects, an independent dose-response relationship between exposure to passive smoking and chronic respiratory disease was observed. Results were not always statistically significant, but the effect was consistently present in each year of the survey, with different spirometric definitions of COPD, with and without respiratory symptoms, with respiratory symptoms alone, and among never smokers as well as the total population. The effect of passive smoking exposure was most marked among never smokers having clinically significant COPD, where never smokers exposed to between 1 and $19 \mathrm{~h}$ of passive smoking had a $52 \%$ excess risk and those exposed to $\geq 20 \mathrm{~h}$ had an excess risk of $98 \%$.

Passive smoking was associated with higher risks of reporting respiratory symptoms (OR 1.68 (1.36 to 2.08)) among never smokers, which is consistent with other European studies, ${ }^{7811}$ although not with a large study in China. ${ }^{12}$ However, it has been shown that symptoms are consistently less likely to be reported in South-East Asia than in Europe. ${ }^{28}$ More women also reported respiratory symptoms, which is similar to findings elsewhere. ${ }^{7}$

It is difficult to compare the results for COPD with other studies as definitions for COPD differ, as do

Table 4 Association between passive smoking and chronic obstructive pulmonary disease among never-smoking participants of the Health Survey for England: effect of alternative spirometric definitions

\begin{tabular}{|c|c|c|c|c|}
\hline & \multicolumn{2}{|l|}{ GOLD criteria* } & \multicolumn{2}{|l|}{ NICE criteria* } \\
\hline & $\begin{array}{l}\text { COPD } \\
\text { Adjusted } \\
\text { OR }(95 \% \mathrm{Cl}) \neq\end{array}$ & $\begin{array}{l}\text { Clinically significant } \\
\text { COPD } \dagger \\
\text { Adjusted } \\
\text { OR }(95 \% \mathrm{Cl}) \ddagger\end{array}$ & $\begin{array}{l}\text { COPD } \\
\text { Adjusted } \\
\text { OR }(95 \% \mathrm{Cl}) \ddagger\end{array}$ & $\begin{array}{l}\text { Clinically significant } \\
\text { COPD } \dagger \\
\text { Adjusted } \\
\text { OR }(95 \% \mathrm{Cl}) \ddagger\end{array}$ \\
\hline$n$ & 7944 & 5443 & 7944 & 5443 \\
\hline \multicolumn{5}{|l|}{ Age (years) } \\
\hline $40-49$ & 1.00 & 1.00 & 1.00 & 1.00 \\
\hline $50-59$ & $1.69(1.32$ to 2.16$)$ & $2.17(1.27$ to 3.71$)$ & $1.85(1.00$ to 3.44$)$ & $3.92(1.06$ to 14.53$)$ \\
\hline $60-69$ & 2.75 (2.17 to 3.49$)$ & 4.14 (2.50 to 6.85$)$ & $5.13(2.96$ to 8.91$)$ & 11.26 (3.33 to 38.05$)$ \\
\hline $70-79$ & 4.48 (3.51 to 5.72$)$ & 8.87 (5.40 to 14.58$)$ & $10.95(6.35$ to 18.86$)$ & 29.68 (8.96 to 98.30$)$ \\
\hline $80+$ & 9.00 (6.80 to 11.92$)$ & 21.81 (12.91 to 36.83$)$ & 18.42 (10.28 to 33.03$)$ & 60.77 (17.83 to 207.18$)$ \\
\hline \multicolumn{5}{|c|}{ 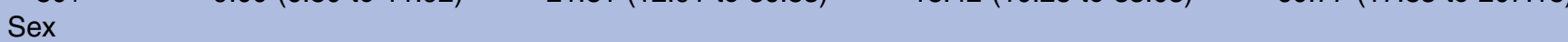 } \\
\hline Male & 1.00 & 1.00 & 1.00 & 1.00 \\
\hline Female & $0.56(0.48$ to 0.66$)$ & $0.62(0.48$ to 0.82$)$ & $0.53(0.40$ to 0.70$)$ & $0.45(0.29$ to 0.69$)$ \\
\hline \multicolumn{5}{|l|}{ Year } \\
\hline 1995 & 1.00 & 1.00 & 1.00 & 1.00 \\
\hline 1996 & $0.76(0.64$ to 0.90$)$ & $0.68(0.52$ to 0.88$)$ & $0.61(0.44$ to 0.84$)$ & $0.57(0.37$ to 0.88$)$ \\
\hline 2001 & 0.67 (0.55 to 0.80$)$ & - & $0.61(0.43$ to 0.86$)$ & - \\
\hline \multicolumn{5}{|c|}{ Passive smoking exposure (h/week) } \\
\hline 0 & 1.00 & 1.00 & 1.00 & 1.00 \\
\hline $1-19$ & $1.11(0.94$ to 1.31$)$ & $1.31(0.98$ to 1.74$)$ & $1.10(0.81$ to 1.49$)$ & $1.09(0.68$ to 1.74$)$ \\
\hline $20+$ & $1.10(0.81$ to 1.49$)$ & $1.82(1.12$ to 2.97$)$ & $1.33(0.74$ to 2.38$)$ & $1.92(0.88$ to 4.23$)$ \\
\hline
\end{tabular}


Table 5 Association between passive smoking, COPD, respiratory symptoms and clinically significant COPD among never-smoking participants of the Health Survey for England (data including participants reporting presence of asthma)

\begin{tabular}{|c|c|c|c|}
\hline & $\begin{array}{l}\text { COPD* }^{\star} \\
\text { Adjusted OR }(95 \% \mathrm{Cl}) \S\end{array}$ & $\begin{array}{l}\text { Respiratory symptoms } \dagger \\
\text { Adjusted OR }(95 \% \mathrm{CI}) \S\end{array}$ & $\begin{array}{l}\text { Clinically significant COPD } \\
\text { Adjusted OR }(95 \% \mathrm{Cl}) \S\end{array}$ \\
\hline$n$ & 8849 & 6004 & 6004 \\
\hline \multicolumn{4}{|c|}{ Age (years) } \\
\hline $40-49$ & 1.00 & 1.00 & 1.00 \\
\hline $50-59$ & $1.06(0.82$ to 1.35$)$ & $1.33(1.14$ to 1.56$)$ & $1.17(0.75$ to 1.82$)$ \\
\hline $60-69$ & 1.30 (1.02 to 1.67$)$ & 2.04 (1.74 to 2.39$)$ & 2.13 (1.41 to 3.22$)$ \\
\hline $70-79$ & 1.88 (1.45 to 2.46$)$ & 2.93 (2.45 to 3.50$)$ & 3.59 (2.35 to 5.49$)$ \\
\hline $80+$ & 2.98 (2.16 to 4.13$)$ & 3.90 (3.06 to 4.96$)$ & 5.54 (3.31 to 9.28$)$ \\
\hline \multicolumn{4}{|l|}{ Sex } \\
\hline Male & 1.00 & 1.00 & 1.00 \\
\hline Female & $0.93(0.78$ to 1.12$)$ & $1.38(1.22$ to 1.56$)$ & $0.96(0.71$ to 1.28$)$ \\
\hline \multicolumn{4}{|l|}{ Asthma } \\
\hline No & 1.00 & 1.00 & 1.00 \\
\hline Yes & 4.51 (3.70 to 5.50$)$ & 7.17 (5.85 to 8.80$)$ & $10.20(7.65$ to 13.59$)$ \\
\hline \multicolumn{4}{|l|}{ Year } \\
\hline 1995 & 1.00 & 1.00 & 1.00 \\
\hline 1996 & $0.81(0.66$ to 0.98$)$ & $0.99(0.88$ to 1.10$)$ & $0.71(0.54$ to 0.94$)$ \\
\hline 2001 & $0.64(0.52$ to 0.80$)$ & - & - \\
\hline \multicolumn{4}{|c|}{ Passive smoking exposure (h/week) } \\
\hline 0 & 1.00 & 1.00 & 1.00 \\
\hline $1-19$ & $1.16(0.97$ to 1.40$)$ & $1.19(1.05$ to 1.34$)$ & $1.19(0.88$ to 1.61$)$ \\
\hline $20+$ & $1.25(0.90$ to 1.72$)$ & 1.70 (1.39 to 2.08$)$ & $1.47(0.89$ to 2.43$)$ \\
\hline
\end{tabular}

passive smoking exposure measures. However, previous studies ${ }^{7} 12-14$ 16-18 have indicated significant increased risk of COPD with increasing passive smoking exposure, with ORs between 1.31 and 2.24, depending on the definitions used and the study design. In China, ${ }^{12}$ being exposed to $\geq 40 \mathrm{~h}$ of passive smoking per week for at least 5 years was associated with risks of spirometrically defined COPD among never smokers of 1.48 (1.18 to 1.85 ). Similarly, in Estonia, for those with more than $5 \mathrm{~h}$ of passive smoking exposure per day outside the home (ie, more than $35 \mathrm{~h} /$ week), the risk of physician-diagnosed chronic bronchitis or emphysema was 1.54 (1.13 to 3.00$){ }^{7}$ For those with $1-5 \mathrm{~h} /$ day $(7-35 \mathrm{~h} /$ week), the risk was lower (OR 1.16 (0.88 to 1.53 )). Passive smoking exposure is lower in England, and likely to have reduced further, subsequent to the collection of our data, since smoking in public places was banned in 2007. Nevertheless, we found that among never smokers with $\geq 20 \mathrm{~h}$ of exposure, there was a risk of 1.17 (0.78 to 1.76$)$ for spirometrically defined COPD, which was between one-third and one-half of the excess risk observed in China or Estonia for approximately half of the reported exposure.

However, risks were highest for never smokers with clinically significant COPD (OR 1.98 (1.03 to 3.79) for $\geq 20 \mathrm{~h}$ of exposure). The greater risks are likely to reflect tighter disease definitions (and more severe disease) and less disease and exposure misclassification. The effects of passive smoking exposure seen with alternative defini- tions of COPD are similar, although lack of statistical significance and more extreme effects of age and sex are likely to reflect less accurate disease definitions. In particular, our results highlight the known age and sex bias inherent in the GOLD and NICE criteria for COPD. ${ }^{29}$

Nevertheless, our calculated risks all fall within the range reported in previous studies, and indicate that our analysis reflects, and adds to, the weight of previous evidence. Our results also accord with published excess risks of passive smoking for heart disease, lung cancer and asthma. 346

\section{Strengths and limitations}

Our study has the advantage of being a large sample representative of the English population, conducted over 3 separate years, with a standardised protocol and objective measure of lung function. There were over 21000 participants, including 8859 never smokers. In addition, we initially excluded those with physician-diagnosed asthma, as some studies have suggested that the effect of passive smoking on lung function is confined to those with increased susceptibility such as asthma, ${ }^{30-32}$ and in order to reduce misclassification of COPD. Our sensitivity analyses demonstrated that the effects show a consistent pattern among those with and without asthma.

However, due to the cross-sectional nature of the design, temporal associations cannot be inferred and it is 
possible that participants with either respiratory symptoms, poorer lung function or a respiratory diagnosis may have modified their exposure to passive smoking. Nonetheless, this would be most likely to manifest in a reduction of their exposure and thus have the effect of underestimating any positive associations between passive smoking exposure and COPD. Additionally, the HSE was not designed for the specific analyses presented in this paper, and thus some of the measures are crude. We used self-reported current passive exposure status, assuming that this would reflect past exposure, although this may have changed over time. In general, passive smoking exposure reduced between 1995 and 2001, and if past exposures were greater, then our analysis may have overestimated the effects at a given exposure level. Also, self-reported exposure is only a proxy for true exposure levels but is accepted as the most practical method of assessment. In addition, the spirometry, while undertaken to a standardised protocol, may not have reached currently recommended quality criteria ${ }^{25}$ and could have misclassified some participants.

Recall bias of passive smoking exposure would not be likely as this is a large survey with many questions and no particular hypothesis associated with respiratory disease.

It is also possible that the observed effects of passive smoking in our analysis may be partly attributable to residual confounding, as any effects of indoor air pollution or occupational exposure could not be accounted for.

In summary, our study, although cross-sectional, lends weight to the argument that passive smoking is an important modifiable risk factor for COPD, and is consistent with other published evidence. In the UK (and many other western countries), passive smoking outside the home has been reducing, although, even after the public smoking ban, $20 \%$ of the adult English population are still exposed to up to $20 \mathrm{~h}$ of passive smoking per week, and $5 \%$ to more than $20 \mathrm{~h} /$ week (unpublished analysis of HSE 2007) ${ }^{33}$ Further investigation is required to determine whether subgroups of the population are experiencing greater exposure in the home since the smoking ban, and what strategies might be effective in reducing their exposure. However, in developing countries, passive smoking is still a major problem in the workplace and policy makers should strive to reduce this.

Acknowledgements We are grateful to the UK Data Archive, University of Essex, and the Health Survey for England 1995, 1996, 2001 and 2007 for providing access to their data.

Correction notice The "To cite: ..." information and running footer in this article have been updated with the correct volume number (volume 1).

Funding Dr Rachel Jordan is funded by a fellowship from the National Institute of Health Research, England (PDF/01/2008/023).

\section{Competing interests None.}

Contributors RJ, PA, KKC and MM contributed to and developed the initial idea. RJ undertook analyses of the HSE. RJ wrote the paper with input and advice from all authors. All authors take responsibility for the integrity of the data and accuracy of the data analysis.
Provenance and peer review Not commissioned; externally peer reviewed.

Data sharing statement No additional data available.

\section{REFERENCES}

1. Lopez A, Mathers CD, Ezzati M, et al. Global Burden of Disease and Risk Factors. Washington, DC: The World Bank, 2006.

2. Mannino D, Buist AS. Global burden of COPD: risk factors, prevalence, and future trends. Lancet 2007;370:765-73.

3. Law MR, Morris JK, Wald NJ. Environmental tobacco smoke exposure and ischaemic heart disease: an evaluation of the evidence. BMJ 1997;315:973-80.

4. Hackshaw AK, Law MR, Wald NJ. The accumulated evidence on lung cancer and environmental tobacco smoke. BMJ 1997;315:980-8.

5. Eisner MD. Clinical year in review III: chronic obstructive pulmonary disease, treatment of tobacco dependence, lung cancer, and lung transplantation. Proc Am Thorac Soc 2009;6:500-5.

6. Jaakkola MS, Jaakkola JJ. Effects of environmental tobacco smoke on the respiratory health of adults. Scand J Work Environ Health 2002;28 Suppl 2:52-70.

7. Larsson ML, Loit LH, Meren M, et al. Passive smoking and respiratory symptoms in the FinEsS Study. Eur Respir J 2003;21:672-6.

8. Leuenberger P, Schwartz J, Ackermann-Liebrich U, et al. Passive smoking exposure in adults and chronic respiratory symptoms (SAPALDIA Study). Swiss Study on Air Pollution and Lung Diseases in Adults, SAPALDIA Team. Am J Respir Crit Care Med 1994:150:1222-8.

9. Lam TH, Ho LM, Hedley AJ, et al. Environmental tobacco smoke exposure among police officers in Hong Kong. JAMA 2000;284:756-63.

10. Ho SY, Lam TH, Chung SF, et al. Cross-sectional and prospective associations between passive smoking and respiratory symptoms at the workplace. Ann Epidemiol 2007;17:126-31.

11. Simoni M, Baldacci S, Puntoni R, et al. Respiratory symptoms/ diseases and environmental tobacco smoke (ETS) in never smoker Italian women Respir Med 2007;101:531-8.

12. Yin $\mathrm{P}$, Jiang $\mathrm{CQ}$, Cheng $\mathrm{KK}$, et al. Passive smoking exposure and risk of COPD among adults in China: the Guangzhou Biobank Cohort Study. Lancet 2007;370:751-7.

13. Eisner MD, Balmes J, Katz PP, et al. Lifetime environmental tobacco smoke exposure and the risk of chronic obstructive pulmonary disease. Environ Health 2005;4:7.

14. Berglund DJ, Abbey DE, Lebowitz D, et al. Respiratory symptoms and pulmonary function in an elderly nonsmoking population. Chest 1999;115:49-59.

15. Forastiere $\mathrm{F}$, Mallone $\mathrm{S}$, Lo Presti $\mathrm{E}$, et al. Characteristics of nonsmoking women exposed to spouses who smoke: epidemiologic study on environment and health in women from four Italian areas. Environ Health Perspect 2000;108:1171-7.

16. Zhou Y, Wang C, Yao W, et al. COPD in Chinese nonsmokers. Eur Respir J 2009;33:509-18.

17. Dennis R, Maldonado JD, Norman S, et al. Woodsmoke exposure and risk for obstructive airways disease among women. Chest 1996;109:115-19.

18. Dayal $\mathrm{HH}$, Khuder S, Sharrar R, et al. Passive smoking in obstructive respiratory diseases in an industrialized urban population. Environ Res 1994:65:161-71.

19. Eisner MD. Secondhand smoke and obstructive lung disease: a causal effect? Am J Respir Crit Care Med 2009;179:973-4.

20. UK Data archive. http://www.data-archive.ac.uk/.

21. Joint Health Surveys Unit of Social and Community Planning Research and University College London. Health Survey for England, 1995 [Computer File]. 3rd edn. Colchester, Essex: UK Data Archive [distributor], 2001. SN: 3796.

22. Joint Health Surveys Unit of Social and Community Planning Research and University College London. Health Survey for England, 1996 [Computer File]. 3rd edn. Colchester, Essex: UK Data Archive [distributor], 2001. SN: 3886

23. National Centre for Social Research and University College London, Department of Epidemiology and Public Health. Health Survey for England, 2001 [Computer File]. 2nd edn. Colchester, Essex: UK Data Archive [distributor], 2004. SN: 4628.

24. Quanjer PH, Tammeling GJ, Cotes JE, et al. Lung volumes and forced ventilatory flows. Report Working Party Standardization of Lung Function Tests, European Community for Steel and Coal. Official Statement of the European Respiratory Society. Eur Respir $J$ Suppl 1993;16:5-40.

25. Pellegrino R, Viegi G, Brusasco V, et al. Interpretative strategies for lung function tests. Eur Respir J 2005;26:948-68.

26. Global Initiative for Chronic Lung Disease. Global Strategy for the Diagnosis, Management and Prevention of Chronic Obstructive 
Pulmonary Disease. 2008. http://www.goldcopd.org/Guidelineitem. asp? $|1=2 \&| 2=1 \&$ intld $=2003$.

27. The National Collaborating Centre for Chronic Conditions. Chronic Obstructive Pulmonary Disease. National clinical guideline on management of chronic obstructive pulmonary disease in adults in primary and secondary care. Thorax 2004;59 Suppl 1:1-232.

28. Wilson D, Takahashi K, Pan G, et al. Respiratory symptoms among residents of a heavy-industry province in China: prevalence and risk factors. Respir Med 2008;102:1526-44.

29. Swanney MP, Ruppel G, Enright PL, et al. Using the lower limit of normal for the FEV1/FVC ratio reduces the misclassification of airway obstruction. Thorax 2008;12:1046-51.

30. Eisner MD. Environmental tobacco smoke exposure and pulmonary function among adults in NHANES III: impact on the general population and adults with current asthma. Environ Health Perspect 2002;110:765-70.

31. Gerbase MW, Schindler C, Zellweger JP, et al. Respiratory effects of environmental tobacco exposure are enhanced by bronchial hyperreactivity. Am J Respir Crit Care Med 2006;174:1125-31.

32. Kunzli N, Schwartz J, Stutz EZ, et al. Association of environmental tobacco smoke at work and forced expiratory lung function among never smoking asthmatics and non-asthmatics. The SAPALDIATeam. Swiss Study on Air Pollution and Lung Disease in Adults. Soz Praventivmed 2000;45:208-17.

33. National Centre for Social Research and University College London, Department of Epidemiology and Public Health. Health Survey for England, 2007 [Computer File]. Colchester, Essex: UK Data Archive [distributor], 2009. SN: 6112. 